\title{
DISCRETE ELEMENT MODELLING OF SINGLE-NAVE CHURCHES DAMAGED AFTER THE 2009 EARTHQUAKE IN L'AQUILA, ITALY
}

\section{FRANCESCA GOBBIN $^{1 *}$, REBECCA FUGGER ${ }^{1}$ AND GIANMARCO DE FELICE $^{1}$}

${ }^{1}$ Department of Engineering, University of Roma Tre

Via Vito Volterra 62, 00146 Rome, Italy

e-mail: francesca.gobbin@uniroma3.it,

rebecca.fugger@uniroma3.it

gianmarco.defelice@uniroma3.it

www.romatrestrutture.eu

Keywords: Churches, Masonry, Distinct Element Method, Rocking domain, Push-over.

\begin{abstract}
The survey of damages after recent earthquakes have shown the fragility of masonry churches against the out-of-plane overturning of the façade. This failure mechanism is currently analyzed having recourse to a rigid body model, using either limit analysis with kinematic approach, or dynamic analysis under rocking motion. However, both the aforementioned methods neglect the interaction with the lateral walls, leading to an underestimation of the effective structural capacity under seismic action. The main goal of this work is therefore to investigate the effect of the interlocking between the façade and the transversal wall and the influence of the quality of masonry in out-of-plane overturning. For this purpose, a refined model of masonry through a Discrete Element Method is developed, based on a detailed recognition of masonry units. The acceleration and displacement capacity are estimated through quasi-static pushover and pulse-based dynamic analyses and compared to those calculated for the rigid body model. The proposed methodology is then applied to a sample of three single-nave masonry churches that suffered damages during the 2009 L'Aquila, Italy earthquake.
\end{abstract}




\section{INTRODUCTION}

Damages experienced during the last seismic events have shown the high vulnerability of masonry churches. These structures, characterized by the absence of horizontal diaphragms connecting the walls, rarely activate a global behavior [1]. Their seismic assessment can be carried out considering distinct macro-elements, having an almost independent structural response under horizontal actions. Indeed, one of the most vulnerable macro-elements is represented by the façade, which may detach from the lateral walls and fail by overturning. Failure may involve the whole height of the façade or only its upper part, due to either a lower connection of the upper part of the façade with the rest of the building or as a consequence of dynamic amplification effects. This mechanism is typical in masonry structures, when the interlocking with side walls is not sufficient to guarantee a box-like behavior. Accordingly, masonry quality and connection with transversal walls play a fundamental role in the structural response under seismic action.

Nowadays, the collapse mechanisms are an effective assessment tool for estimating the seismic acceleration capacity [2], either through the kinematic approach of Limit Analysis [3], or by integrating the equation of rocking motion [4], as well as by considering an equivalent single degree of freedom oscillator. However, all of these models are usually based on the assumption that the façade is detached from the lateral walls and behaves as a rigid body overturning around a hinge at its basis.

Aiming at understanding the role of the connections and their influence on the effective

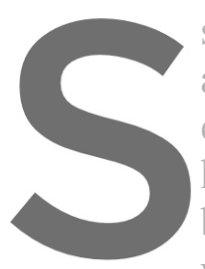
seismic behavior, in the present paper the stabil
and the lateral walls is investigated through a b
effectiveness of the DEM to capture the behav
has already been proved in the Literature [6-1
based on the assumption that all the non-linear

while these latter can be considered simply
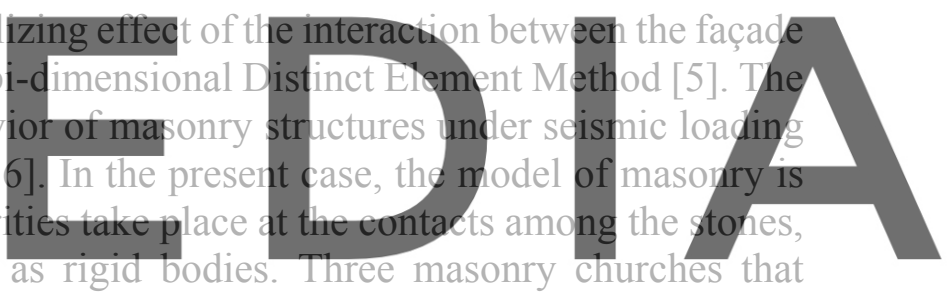

suffered damages from the 2009.L'Aquila (Italy) earthquake are analyzed through both,

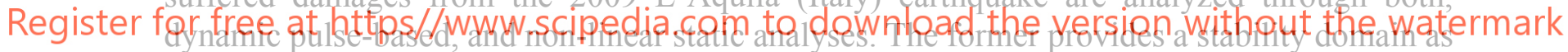

a function of pulse amplitude and duration that is compared with the unilateral rocking domain

of a rigid biock [17]. The latter provides the acceleration and dispiacement capacity under quasi-static horizontal loading, as compared to those obtained according to the rigid block schematization $[10,18]$.

\section{THE RIGID BODY MODEL}

Consider the façade of the church as the rigid body shown in Figure 1, where $b_{f}, h_{f}, R, W$ correspond, respectively, to the thickness, height, semi-diagonal and weight of the façade, while $\alpha$ is the slenderness angle. The dynamic behavior can be analyzed through the inverted pendulum [4], whose configuration is defined by the rotation $\theta$ towards the outside. Indeed, the rotation towards the inside is constrained by the lateral walls. For slender blocks $\left(\alpha<20^{\circ}\right)$, the slenderness angle $\alpha$ and the horizontal displacement of the center of gravity $u$ can be approximated, respectively, as:

$$
\alpha=\frac{b_{f}}{h_{f}} ; \quad u=\frac{h_{f}}{2} \theta
$$




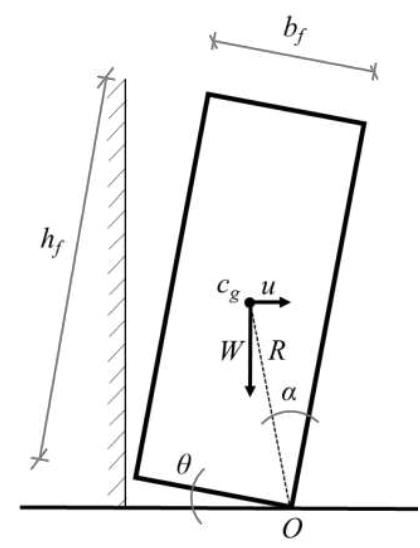

Figure 1: Rigid body model during rocking motion

\section{Let us first consider the structure subjected to a quasi-static horizontal base acceleration $a$.} The motion takes place only when the base acceleration reaches the value $a^{*}=\alpha g$, which activates the mechanism, where $g$ is the acceleration of gravity. The capacity curve is shown in Figure 2, consisting in an ascending rigid branch corresponding to the absence of motion and a descending branch that, for slender blocks, can be approximated by a linear curve from $a^{*}$ to the ultimate displacement $d_{u}$.
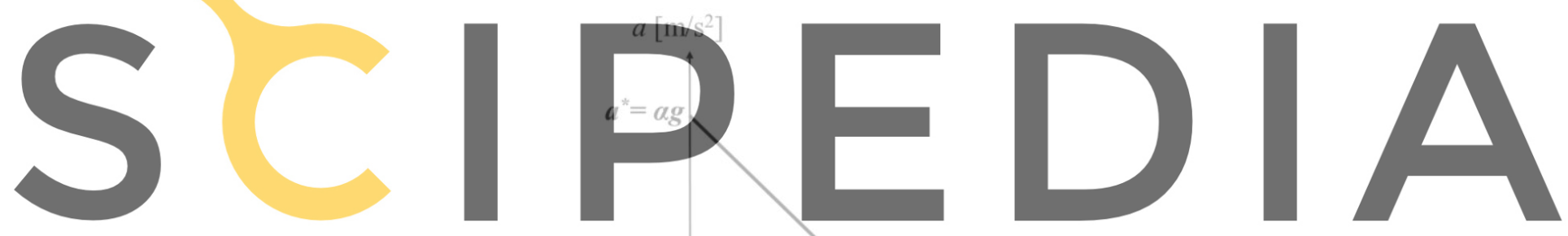

Register for free at https//www.scipedia.com to download the version without the watermark

Figure 2: Capacity curve of a rigid body

According to Figure 2, the structure under earthquake base-motion starts rocking when the acceleration reaches the value $a^{*}$ but does not collapse until the displacement exceeds the ultimate value $d_{u}$.

Let us now consider the structure subjected to a semi-sinusoidal pulse, given by the following base acceleration, $a(t)$ acting for a time interval $t_{0}$ :

$$
a(t)=\left\{\begin{array}{cc}
-a_{0} \sin \left(\omega_{0} t+\psi\right), & t \leq t_{0} \\
0, & t>t_{0}
\end{array}\right.
$$

where $t_{0}=\pi / \omega_{0}$ represents half of the semi-sinusoidal acceleration period.

This schematization of earthquake input has been used in the past, especially in the description of near-fault events [19] and has the advantage of leading to an analytical expression for out-of-plane overturning, as shown hereafter. According to Housner, the equation of motion can be written as: 


$$
I_{o} \ddot{\theta}=-W R \sin (\alpha-\theta)+W R \frac{a_{0}}{g} \sin \left(\omega_{0} t+\psi\right)
$$

Assuming the hypothesis of slender blocks and settling $p^{2}=\frac{W R}{I_{o}}$, the equation of motion becomes:

$$
\ddot{\theta}-p^{2} \theta=\alpha p^{2}\left[\frac{\sin \left(\omega_{0} t+\psi\right)}{\sin \psi}-1\right]
$$

By assigning the initial conditions and imposing the equilibrium in the limit configuration $\theta=\alpha$, the following expression is obtained:

$$
\frac{a_{0}}{g \alpha}=\sqrt{1+\frac{I_{o}}{W R} \omega_{0}^{2}}
$$

Equation 5 represents the limit condition in terms of pulse amplitude $a_{0}$ and duration to beyond which the collapse by overturning takes place.

\section{THE NUMERICAL DISCRETE ELEMENT MODEL}

The Discrete Element Method was originally proposed for the study of rocks mechanics [20] and then widely applied to the study of the seismic behavior of masonry structures [6-15], thanks to its capability of modeling the cracks and discontinuities taking place at collapse.

In the present paper, the blocks are considered as rigid bodies, while the contacts modelled as two couple the basis of the overall particular, aiming at umping in the contact the normal stiffness depends on the average block contact stiffness can be approximated as half of the normal stiffness. The strength of the contact A Register for controlled by the Coulomb condition $|\tau| \leq \sigma \cdot \tan (\varphi)$ neglecting cohesion and tensile strength,

\subsection{Viesh modelling}

In order to reduce the computational effort of the analysis, a bi-dimensional model has been used. The DEM mesh is based on the survey of masonry, aiming at reproducing, as far as possible, the effective shape of the stones. In order to take into account tridimensional effects, the blocks density and contacts stiffness are affected by the third dimension, i.e. the length of the façade, or the thickness of the lateral wall, as shown in Figure 3. The façade and the side wall heights are respectively denoted as $h_{f}$ and $h_{s}$, while their thickness as $b_{f}$ and $b_{s}$. The façade length is denoted by $l_{f}$, while $l_{s}$ represents the length of the portion of the side wall adjacent to the façade that is explicitly modeled, while the rest of the lateral wall is simply considered as an elastic block. The structure is finally laid on a rigid block, constituting the base to which seismic motion is applied. 


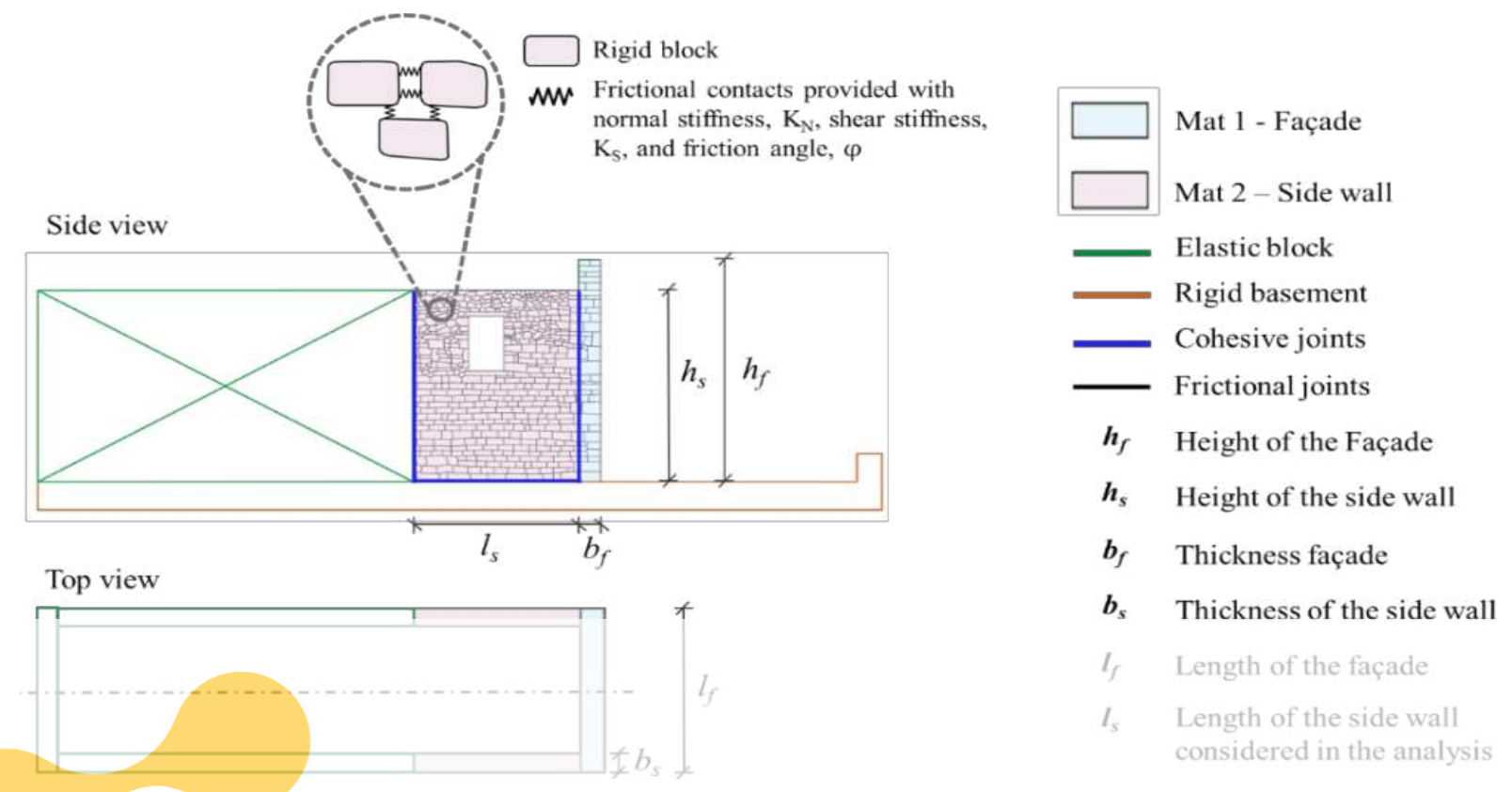

Figure 3: Interface model and framework of the mesh for a bi-dimensional model.

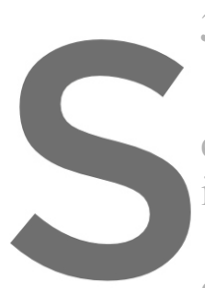

\subsection{Seismic Input definition}

Both, pushover and consider the artificial d

in the latter.

The algorithm for pushover analysis applies

centroids of each block, controlling the unbalanced forces
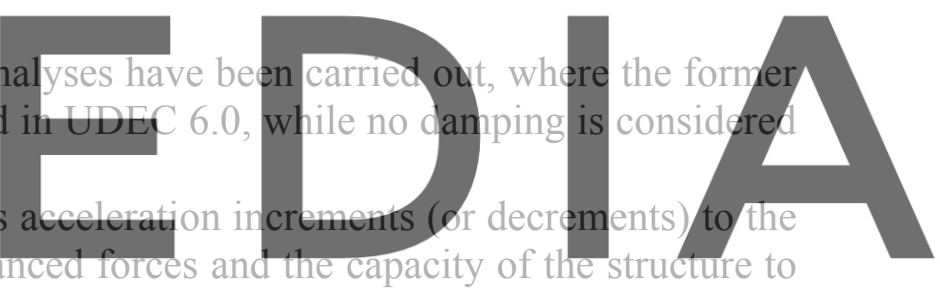

transfer the horizontal action into base shear. Both, the ascending and descending branches of

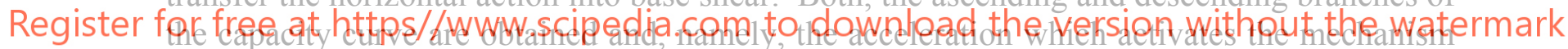

\section{$a^{*}$ and the ultimate displacement $d u$.}

The algorithm for puise-based analysis applies a semi-sinusoidal acceleration to the centroid of each block in a sequence of analyses for increasing pulse amplitude or duration. The overcoming of the maximum displacement and the consequent collapse of the façade is automatically recognized, providing ultimate displacement capacity and the corresponding pulse action. The unilateral equilibrium rocking domain is finally obtained for varying pulse amplitude $a_{0}$ and duration to through an automatic procedure implemented in Fish language [5].

\section{CASE OF STUDIES}

Three case studies have been considered for the application of the above described procedure for seismic assessment, namely the church of Santa Maria degli Angeli, the church of San Paolo ad Peltuinum and the church of San Sisto, all located in the area surrounding the city of L'Aquila, as shown in Figure 4.

In the next three sections the churches are briefly described, and their geometrical and mechanical properties are provided. Referring to Figures 5-7, $l_{f} \& b_{f}\left(l_{s} \& b_{s}\right)$ are the length and the thickness of the façade (of the lateral wall) $h_{f} \& h_{s}$ their height, $\gamma_{f} \& \gamma_{s}$ their specific weight, 
$K_{N f} \& K_{N s}$ their normal joint stiffness, $K_{S f} \& K_{S s}$ their shear joint stiffness, while the friction angle $\varphi$ in the contacts is set equal to $30^{\circ}$ for all the analyses.

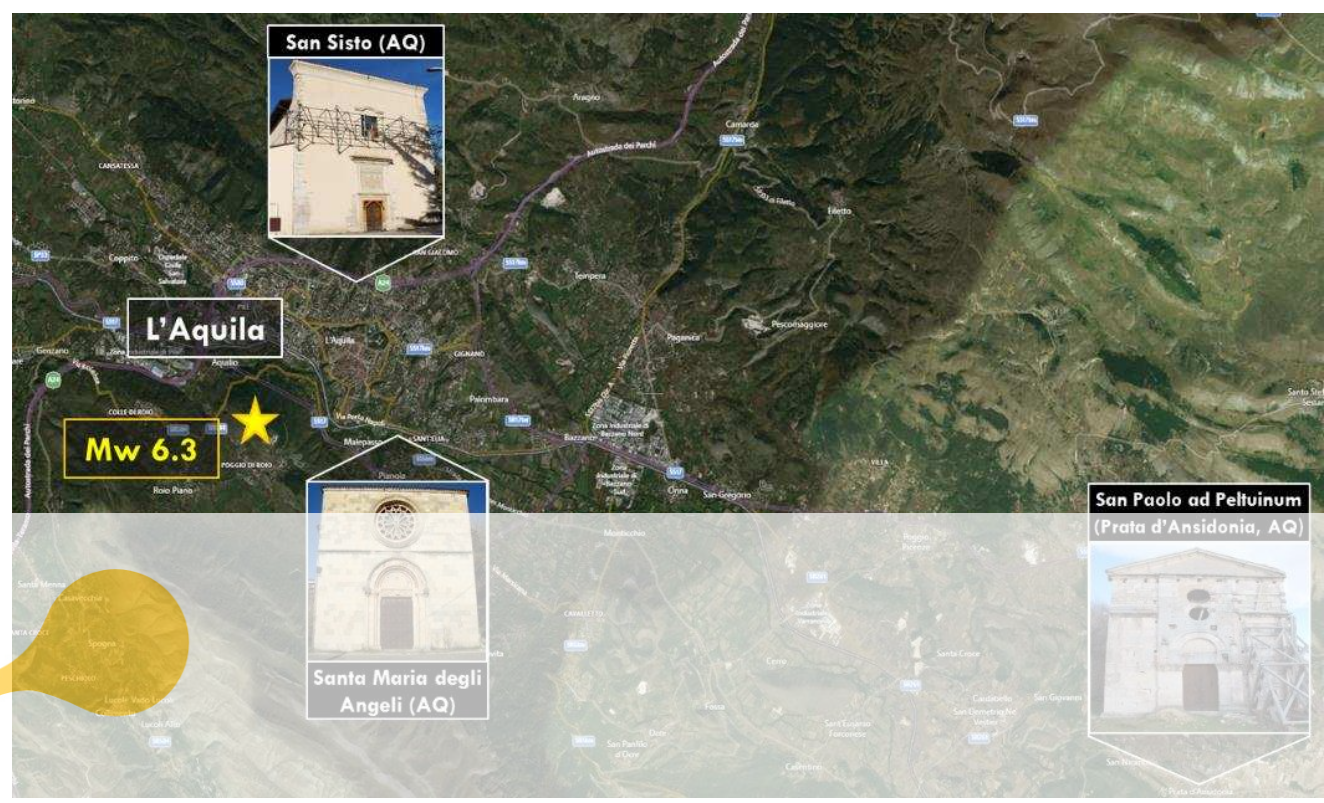

Figure 4: Location of the case studies and the epicenter of the 2009 L'Aquila earthquake.

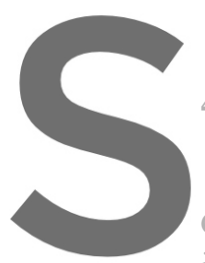

4.1 Santa Maria degli Angeli
The Church of Santa Marid degli Angeli has an almost rectangular plan, with a
of about $10 \mathrm{~m}$ and a length of $16 \mathrm{~m}$. The niches along the nave show the signs of

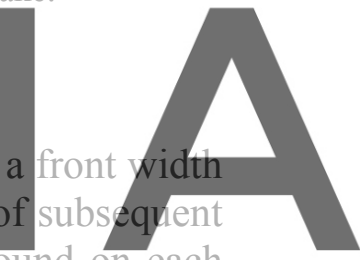

infill and repeated rearrangements. Two regular rectangular windows can be found on each side, next to the connection with the facade. Masonry is made of small and poorly worked Register fabfreg-atupttps//WwW.scipedia.com to download the version without the watermark

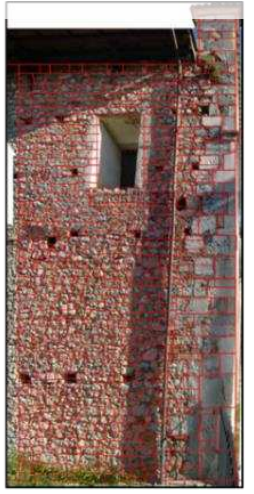

A)

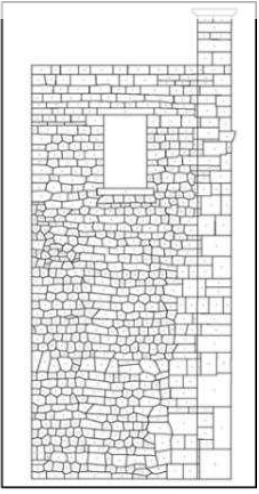

B)

\begin{tabular}{lcc}
\hline & Façade & Side wall \\
\hline$l_{f} \& b_{s}[\mathrm{~m}]$ & 10.00 & 0.50 \\
\hline$l_{s} \& b_{f}[\mathrm{~m}]$ & 0.90 & 4.30 \\
\hline$h_{f} \& h_{s}[\mathrm{~m}]$ & 10.00 & 8.80 \\
\hline$\gamma_{f} \& \gamma_{s}\left[\mathrm{Kg} / \mathrm{m}^{3}\right]$ & 2100 & 2000 \\
\hline$K_{N f} \& K_{N s}[\mathrm{~Pa} / \mathrm{m}]$ & $2.90 \mathrm{e} 10$ & $4.10 \mathrm{e} 10$ \\
\hline$K_{S f} \& K_{S s}[\mathrm{~Pa} / \mathrm{m}]$ & $8.31 \mathrm{e} 9$ & $1.35 \mathrm{e} 9$ \\
\hline$\varphi[\mathrm{deg}]$ & $30^{\circ}$ & $30^{\circ}$ \\
\hline
\end{tabular}

Figure 5: Church of Santa Maria degli Angeli: A) Block masonry recognition; B) Discrete element model; table of the main geometric and mechanical properties 


\subsection{San Paolo ad Peltuinum}

The Church of San Paolo ad Peltuinum is located in the municipality of Prata d'Ansidonia (AQ). The structure was probably built between the VII and VIII century a.c. At least five stages of evolution and transformation of the building can be identified, related to the Lombard, Benedictine, Cistercian, Renaissance and eighteenth century influences. The church presents a cross plan with a single nave and a transept. Two different types of masonry can be noticed. The lower part is made of parallelepipedal larges blocks and dates back to medieval period, while the upper part, made of small irregular stones, is the result of a more recent reconstruction (Figure 6).

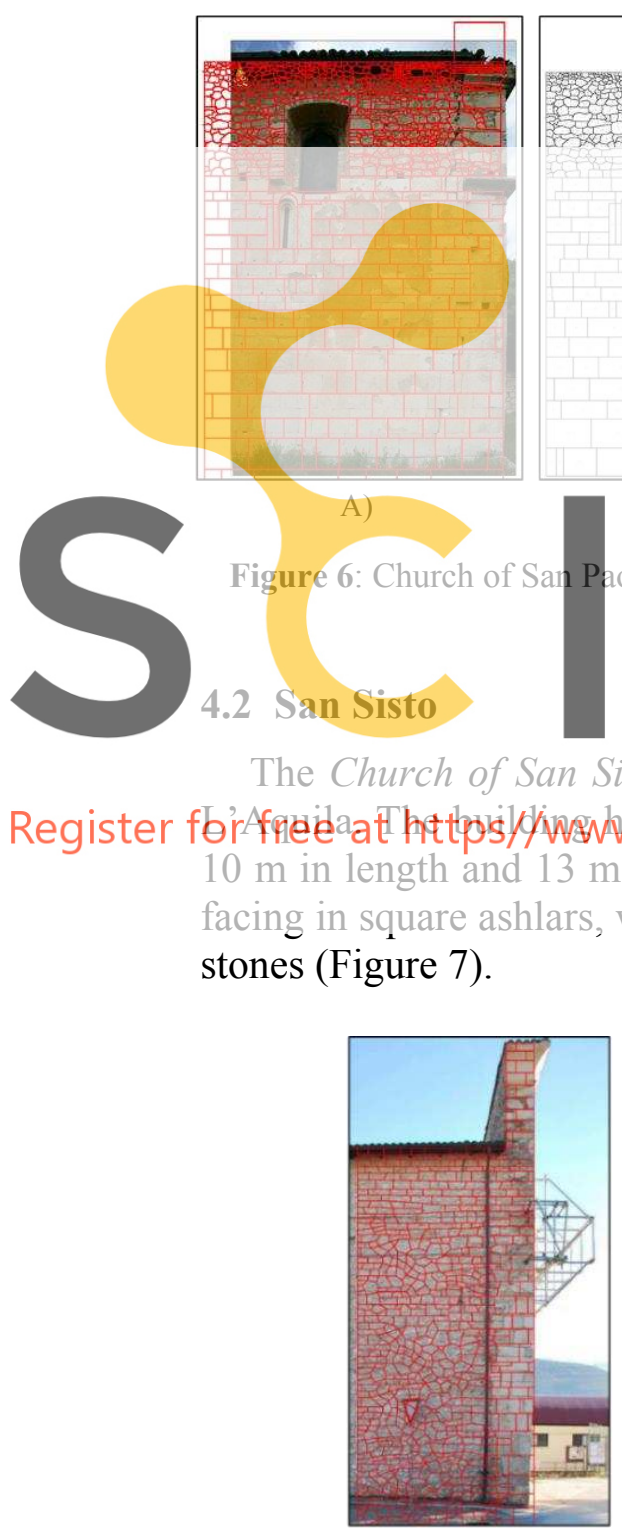

A)

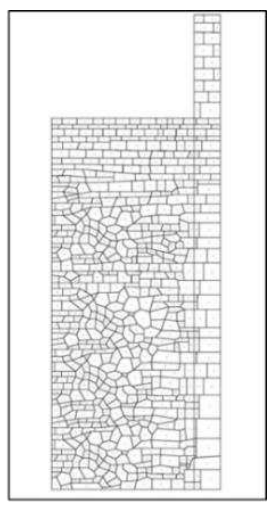

B)

\begin{tabular}{|c|c|c|c|c|}
\hline & \multicolumn{2}{|c|}{ Façade } & \multicolumn{2}{|c|}{ Side wall } \\
\hline & upper & lower & upper & lower \\
\hline$l_{f} \& b_{s}[\mathrm{~m}]$ & \multicolumn{2}{|c|}{8.00} & \multicolumn{2}{|c|}{0.80} \\
\hline$l_{s} \& b_{f}[\mathrm{~m}]$ & \multicolumn{2}{|c|}{1.00} & \multicolumn{2}{|c|}{5.50} \\
\hline$h_{f} \& h_{s}[\mathrm{~m}]$ & \multicolumn{2}{|c|}{9.60} & \multicolumn{2}{|c|}{8.80} \\
\hline$\gamma_{f} \& \gamma_{s}\left[\mathrm{Kg} / \mathrm{m}^{3}\right]$ & 1900 & 2200 & 1900 & 2200 \\
\hline$K_{N f} \& K_{N s}[\mathrm{~Pa} / \mathrm{m}]$ & $2.19 \mathrm{e} 10$ & $2.69 \mathrm{e} 10$ & $6.96 \mathrm{e} 9$ & $2.85 \mathrm{e} 9$ \\
\hline$K_{S f} \& K_{S s}[\mathrm{~Pa} / \mathrm{m}]$ & $7.30 \mathrm{e} 9$ & $8.97 \mathrm{e} 9$ & $2.32 \mathrm{e} 9$ & $9.50 \mathrm{e} 8$ \\
\hline$\varphi[\mathrm{des}$ & $30^{\circ}$ & & $30^{\circ}$ & $30^{\circ}$ \\
\hline
\end{tabular}
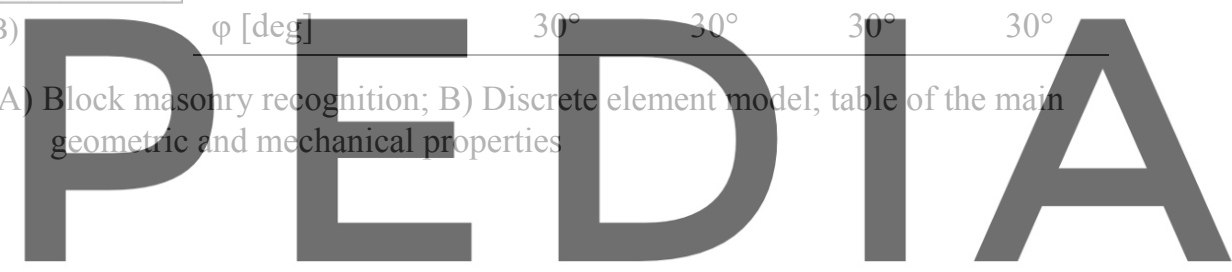

to the VIII century a.C. and is located in the city of 


\section{RESULTS}

In this section, the numerical and analytical results obtained for the three cases of study are presented. The stability domain under sinusoidal pulses, and the pushover curve obtained through DEM are compared, respectively, to the analytical rocking domain and to the capacity curve of the rigid block. The comparison shows to what extent the connection with lateral walls may be effective in the seismic assessment of the church against the overturning of the façade.
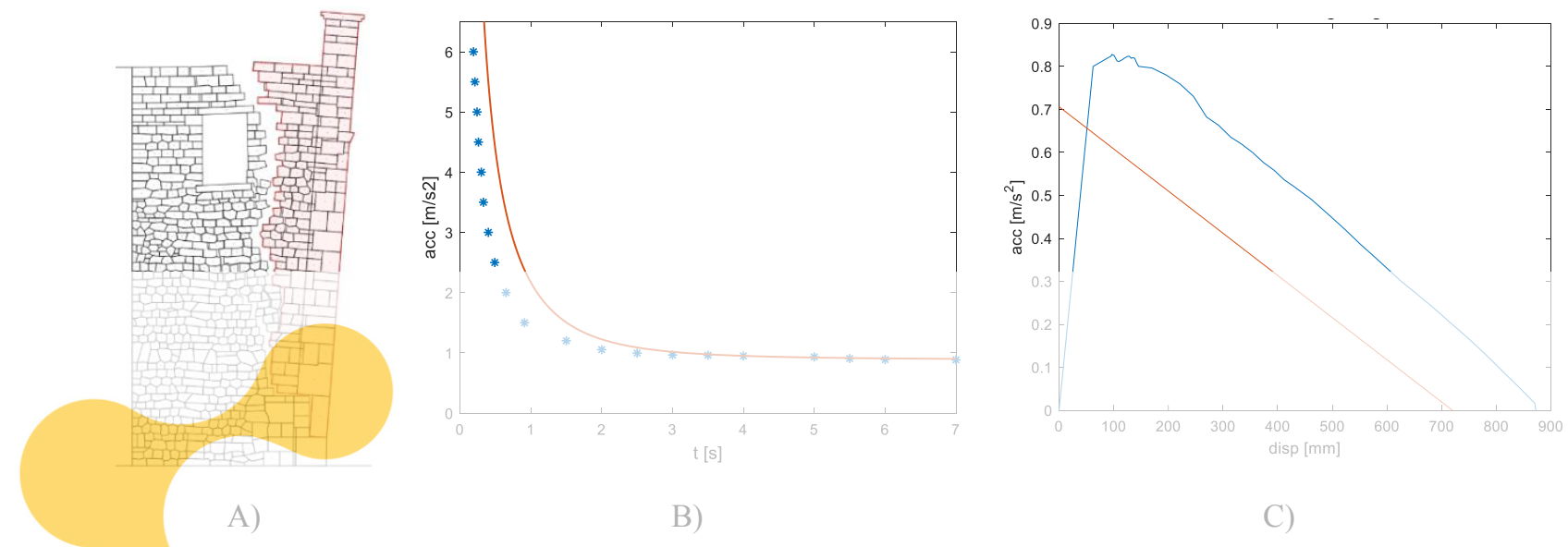

Figure 8: Church of Santa Maria degli Angeli: A) Predicted crack pattern and failure mechanism according to
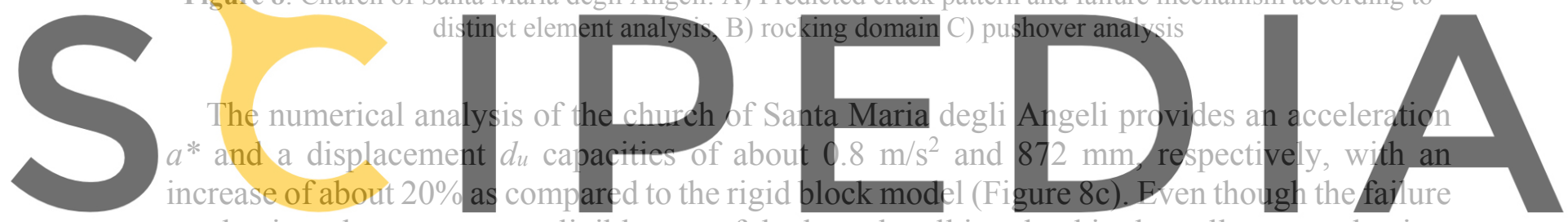

mechanism shows a non-negligible part of the lateral wall involved in the collapse mechanism

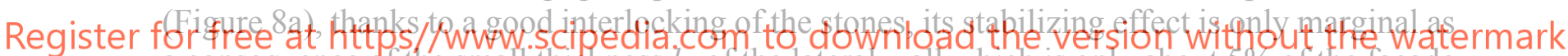
a consequence of the small thickness $b_{s}$ of the lateral wall which is only about 5\% of the facade length.

The analysis of the church of San Paolo exhibits a strong increase (of about 50\%) in acceleration capacity and almost no increment in displacement capacity when compared to the rigid block. Thanks to the quality of masonry, made of large squared blocks in the basement of the church, the rotation hinge is located at the middle of the façade height (Figure 9a). Therefore, the acceleration capacity increases according to the lower slenderness of the part involved in overturning, while the displacement capacity, which is governed by the façade thickness, remains almost unchanged.

The analysis of the church of San Sisto (Figure 10), shows an increase in both acceleration and displacement capacity of about $65 \%$, thanks to the beneficial effect of the connection between the façade and the transversal wall. Nonetheless, the acceleration capacity $a^{*}$ determined by the DEM, equal to $0.9 \mathrm{~m} / \mathrm{s}^{2}$ is still low, due to the high slenderness of the façade. 


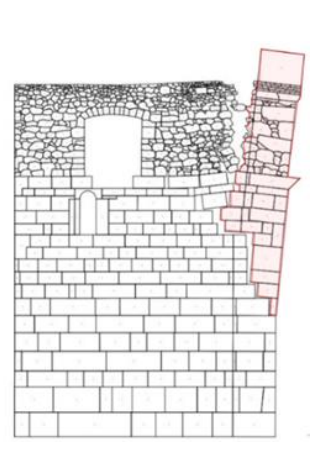

A)

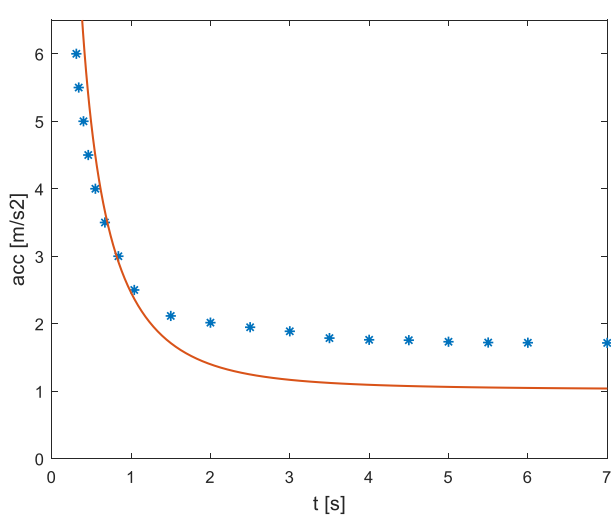

B)

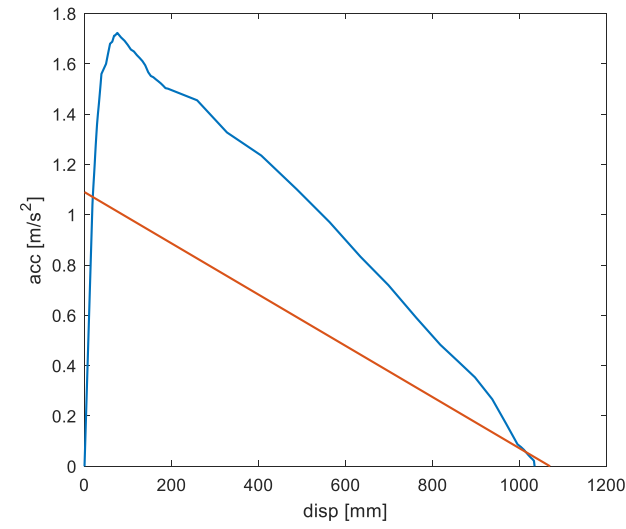

C)

Figure 9: Church of San Paolo: A) Predicted crack pattern and failure mechanism according to distinct element analysis, B) rocking domain C) pushover analysis.
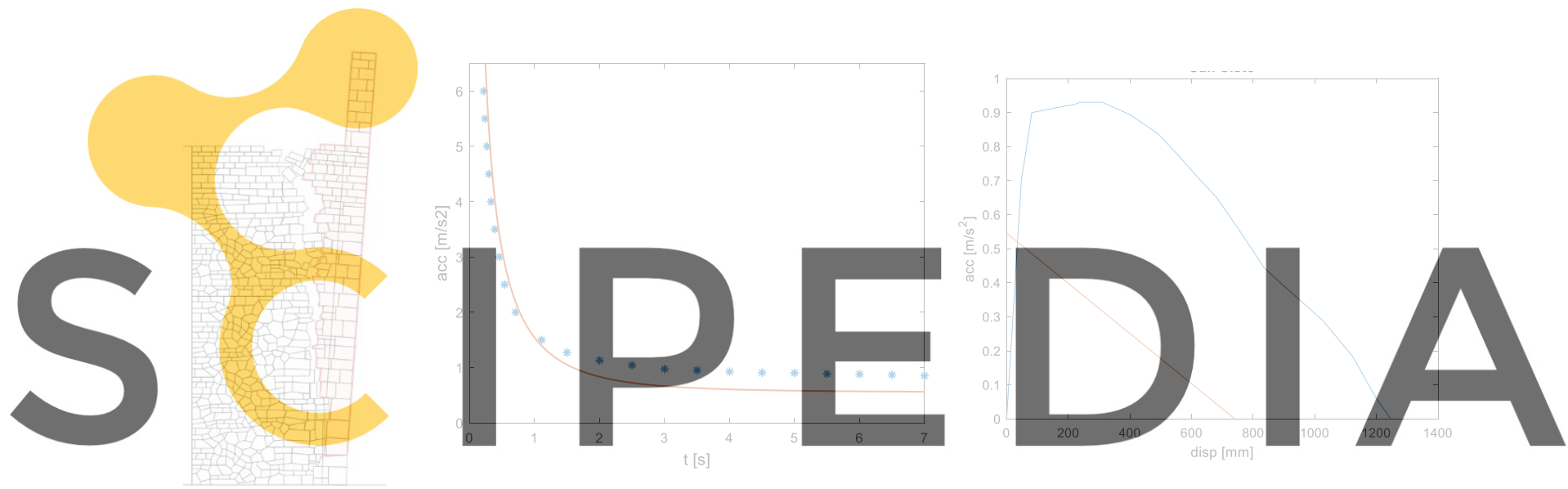

Register for freeatt https//www.scipediascom to download the version without the watermark

Figure 10: Church of San Sisto: A) Predicted crack pattern and failure mechanism according to distinct element analysis, B) rocking domain C) pushover analysis.

The results shown for the three churches under study suggest that the analytical rigid block model generally constitutes a powerful and effective instrument for the seismic assessment of masonry churches. Only when the characteristics of masonry are such as to prevent the complete detachment of the façade, the rigid block only provides a lower bound estimate. In this case, the lateral walls play a non-negligible effect in terms of both, higher hinge position (i.e. lower slenderness of the part undergoing overturning) and stabilizing bending moment against overturning.

\section{CONCLUSIONS}

In this paper, an approach for modelling the collapse mechanism of historical masonry building and evaluating the reliability of current models used for seismic assessment is outlined. The seismic response of three single-nave churches that suffered damages after the 2009 L'Aquila earthquake is investigated through pulse-based dynamic and quasi-static pushover 
analyses, with both analytical and numerical approach. The well-known mechanism of overturning of the façade is considered and the numerical results are compared with those derived neglecting the connections and modelling the façade as a rigid block according to the Housner rocking model.

Through the detailed reconstruction of masonry pattern, the numerical analyses with DEM take into account the effect of connections due to interlocking of stones, resulting in the increase of both acceleration and displacement capacities. The proposed approach succeeds in detecting the expected failure mechanism, which does not change from quasi-static to dynamic loading. Only for short period pulses, the numerical model provides a widespread crack pattern and a slight decrease in seismic acceleration capacity.

Beside the differences that may become relevant for high quality masonry, the rigid block model still represents a powerful and effective tool for the seismic assessment of collapse mechanisms.

Acknowledgements. The present research has been funded by ReLUIS-DPC 2019-2021 and Regione Lazio SICURA research projects. The authors gratefully acknowledge Itasca Consulting Group for providing the web-licenses of UDEC 6.0.

\section{REFERENCES}

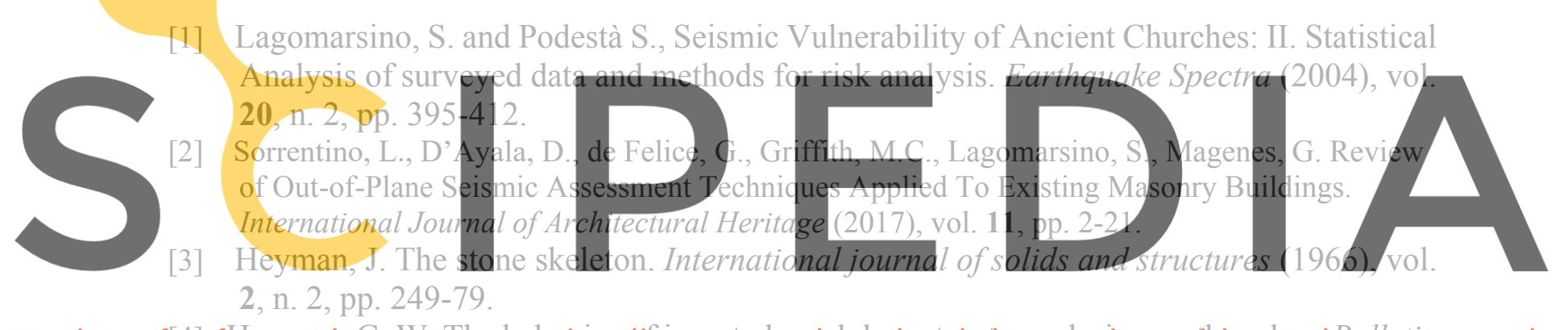

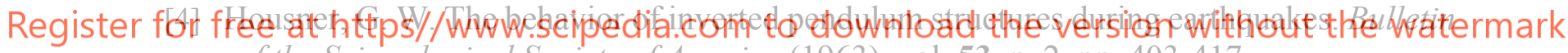
of the Seismological Society of America (1963), vol. 53, n. 2, pp. 403-417.

[5] ITASCA consulting group, UDEC (Universal Distinct Element Code) Version 6.0 (2017), Minneapolis, Minnesota.

[6] Azevedo, J., Sincraian, G., Lemos J.V. Seismic behavior of blocky masonry structures. Earthquake Spectra (2000), vol. 16, n. 2, pp. 337-365.

[7] Lemos, J.V. Discrete Element Modeling of Masonry Structures. International Journal of Architectural Heritage (2007), vol. 1, n. 2, pp. 190-213.

[8] de Felice, G. and Mauro, A. On Overturning of the Façade in Churches with Single Nave: Some Case Studies from L'Aquila, Italy, 2009 Earthquake. Advanced Materials Research (2010), vol. 133-134, pp. 807-812.

[9] Gobbin, F., Fugger, R. and de Felice, G. Modellazione agli elementi distinti per lo studio dell'interazione della facciata con la parete laterale di alcune chiese nel territorio Aquilano. In: ANIDIS (2019).

[10] de Felice, G. Out-of-plane seismic capacity of masonry depending on wall section morphology. International Journal of Architectural Heritage (2011), vol. 5, n. 4-5, pp. 466-482.

[11] Al Shawa, O., de Felice, G., Mauro A., and Sorrentino L. Out-of-plane seismic behaviour 
of rocking masonry walls. Journal of earthquake engineering (2012), vol. 41, n. 5, pp. 949-968.

[12] de Felice, G., De Santis, S., Lourenço, P.B., Mendes, N. Methods and Challenges for the Seismic Assessment of Historic Masonry Structures. International Journal of Architectural Heritage (2017), vol. 11, pp. 143-160.

[13] Malomo, D., De Jong, M.J. and Penna, A. Distinct Element modelling of the in-plane cyclic response of URM walls subjected to shear-compression. Earthquake Engineering and Structural Dynamics (2019), vol. 48, n. 12, pp 1322-1344.

[14] Meriggi, P., de Felice, G., De Santis, S., Gobbin, F., Mordanova, A. and Pantò, B. Distinct Element Modelling of masonry walls under out-of-plane seismic loading. International journal of architectural heritage (2019), vol. 13, n. 7, pp. 1110-1123.

[15] Lemos, J.V. Discrete Element Modeling of the Seismic Behaviour of Masonry Constructions. Buildings (2019), vol. 9, n. 2, pp. 43-53.

[16] Malena, M., Portioli, F., Gagliardo, R., Tomaselli, G., Cascini, L. and de Felice, G. Collapse mechanism analysis of historic masonry structures subjected to lateral loads: A comparison between continuous and discrete models. Computers \& Structures (2019), vol. 220, pp. 14-31.

[17] Mauro, A., de Felice, G. and De Jong, M. J. The relative dynamic resilience of masonry collapse mechanism. Engineering Structures (2015), vol. 85, pp. 182-194.

[18] Mordanova, A., de Felice, G. Seismic assessment of archaeological heritage using discrete element method. International Journal of Architectural Heritage (2018), DOI: 10.1080/15583058.2018.1543482

[19] Makris, N. and Roussos, Y. Rocking response of rigid blocks under near-source ground motions. Géotechnique (2009), vol. 50, n. 3, pp. 243-262.

[20] Cundall, P. A. A computer Model for Simulating Progressive Large-Scale Movements in Blocky Rock Systems. Proceeding of the Symposium of the International Society of Rock Mechanics (1971). 